\title{
Extracorporeal life support as bridge to lung transplantation: a systematic review
}

\author{
Davide Chiumello ${ }^{1,2^{*}}$, Silvia Coppola ${ }^{1,2}$, Sara Froio ${ }^{1,2}$, Andrea Colombo ${ }^{2}$ and Lorenzo Del Sorbo ${ }^{3,4}$
}

\begin{abstract}
Introduction: Patients with acute respiratory failure requiring respiratory support with invasive mechanical ventilation while awaiting lung transplantation are at a high risk of death. Extracorporeal membrane oxygenation $(E C M O)$ has been proposed as an alternative bridging strategy to mechanical ventilation. The aim of this study was to assess the current evidence regarding how the ECMO bridge influences patients' survival and length of hospital stay.

Methods: We performed a systematic review by searching PubMed, EMBASE and the bibliographies of retrieved articles. Three reviewers independently screened citation titles and abstracts and agreement was reached by consensus. We selected studies enrolling patients who received ECMO with the intention to bridge lung transplant. We included randomized controlled trials (RCTs), case-control studies and case series with ten or more patients. Outcomes of interest included survival and length of hospital stay. Quantitative data summaries were made when feasible.
\end{abstract}

Results: We identified 82 studies, of which 14 were included in the final analysis. All 14 were retrospective studies which enrolled 441 patients in total. Because of the broad heterogeneity among the studies we did not perform a meta-analysis. The mortality rate of patients on ECMO before lung transplant and the one-year survival ranged from $10 \%$ to $50 \%$ and $50 \%$ to $90 \%$, respectively. The intensive care and hospital length of stay ranged between a median of 15 to 47 days and 22 to 47 days, respectively. There was a general paucity of high-quality data and significant heterogeneity among studies in the enrolled patients and technology used, which confounded analysis.

Conclusions: In most of the studies, patients on ECMO while awaiting lung transplantation also received invasive mechanical ventilation. Therefore, whether ECMO as an alternative, rather than an adjunction, to invasive mechanical ventilation is a better bridging strategy to lung transplantation still remains an unresolved issue. ECMO support as a bridge for these patients could provide acceptable one-year survival. Future studies are needed to investigate ECMO as part of an algorithm of care for patients with end-stage lung disease.

\section{Introduction}

Lung transplant is considered an established treatment for patients with end-stage chronic respiratory failure [1]. Since the first successful report in 1983 by Cooper and colleagues [2], more than 30,000 lung transplants have been done worldwide [3]. The significantly larger number of candidates than available organs explains the long waiting times and high risk of perioperative morbidity and mortality

\footnotetext{
* Correspondence: chiumello@libero.it

'Dipartimento di Anestesia, Rianimazione (Intensiva e Subintensiva) e Terapia del Dolore, Fondazione IRCCS Ca' Granda, Ospedale Maggiore Policlinico, Via F. Sforza 35, 20122 Milano, Italy

2Dipartimento di Fisiopatologia Medico-Chirurgica e dei Trapianti, Università degli Studi di Milano, Milano, Italy

Full list of author information is available at the end of the article
}

[1,4-6]. Contributing to this high mortality rate is also the lack of efficacious and safe means of artificial respiratory support for patients awaiting the transplant once they develop acute respiratory failure with refractory hypoxemia and hypercapnia $[4,7]$. Mechanical ventilation per se can aggravate acute respiratory failure and hemodynamic instability, increasing the risk of ventilator-associated pneumonia and ventilator-induced lung injury [7-10]. Mechanically ventilated pre-transplant patients have been reported to have significantly higher post-transplant mortality rates than non-ventilated patients $[11,12]$.

More than three decades ago, extracorporeal membrane oxygenation (ECMO) was introduced to manage patients on the lung transplant waiting list who were 
dying of acute respiratory failure refractory to mechanical ventilation $[4,13]$. The first report of ECMO as a feasible bridging strategy to transplantation goes back to 1975: the patient survived transplantation but died shortly after from complications of infection [14]. After a randomized trial that suggested that ECMO was associated with a worse outcome than mechanical ventilation in patients with acute respiratory failure [15], ECMO as a bridge to lung transplant fell into disuse [4].

More recently, however, thanks to improvements in technology, safety profile and manageability of extracorporeal life support strategies [16,17], ECMO has been reintroduced in some centers as an option for patients with severe respiratory failure awaiting lung transplant $[4,10,13,18-22]$. The number of lung transplant candidates who could benefit from ECMO is now significantly larger $[13,19,20,22]$. A report by the United Network of Organ Sharing (UNOS) showed that, despite its complexity and side effects, the use of ECMO as a bridge to lung transplant has risen by $150 \%$ in the two last years compared to the previous decades (1970 to 2010) [4]. However, given the small numbers of transplantable lungs, bridging lungtransplant candidates on ECMO has raised ethical concerns about the risk of potentially selecting for transplantation, very severely ill patients with the risk of poor posttransplant outcome. Instead, according to the lung allocation score (LAS) system, organs should be allocated to patients who have the greatest need, such as those on ECMO, but who are also likely to benefit most from the transplant $[5,6,23,24]$.

In this perspective, new advances have demonstrated the potential of ECMO as an alternative to mechanical ventilation in awake, spontaneously breathing patients. With awake-ECMO patients preserve their muscle tone, with greater possibility of early mobilization and participation in intensive physical therapy, thus improving their condition before a lung transplant and making for a better post-transplant outcome [20,25-29].

Given the lack of definitive data on the efficacy of ECMO as bridge to lung transplantation, and the consequent lack of a clear consensus on this strategy [6], we conducted a systematic review to assess the current evidence on the use of ECMO in patients with advanced respiratory failure awaiting lung transplant.

\section{Materials and methods}

\section{Search strategy and selection of studies}

Our search used the statement - preferred reporting items for systematic reviews and meta-analyses (PRISMA) - as a guide [30]. We made a computerized search of MEDLINE/PubMED and EMBASE databases from January 2000 to June 2014. Our search was limited to studies on humans and adults. We limited the selection to studies written in English, French, German or Spanish. We used the following search keywords and terms: "preoperative extracorporeal membrane oxygenation" OR "preoperative ECMO" AND "lung transplantation", "extracorporeal membrane oxygenation" OR "ECMO" AND "bridge to lung transplantation", "ambulatory extracorporeal membrane oxygenation" OR "ambulatory ECMO" AND "lung transplantation".

Three reviewers (DC, SC and SF) independently screened citation titles and abstracts. We looked through the references of all articles retrieved and reviewed the articles to identify additional potentially eligible studies. In case of disagreement the authors reviewed the article in question together until they reached a consensus. We deleted duplicate papers. All potentially eligible papers were retrieved in full and assessed to confirm eligibility.

We screened studies for relevance that enrolled patients awaiting lung transplant who were admitted to ICU to receive ECMO support as a bridging procedure, including veno-venous approach and veno-arterial support. We excluded studies that enrolled patients treated with pump-free extracorporeal interventional lung-assist devices. We included studies enrolling at least ten patients on ECMO bridging. Data were abstracted in duplicate by two reviewers (SC and SF) and any discrepancies were solved by discussion.

The following information was collected in a datasheet: publication (first author's name, year, journal), study design, number of enrolled patients on ECMO bridge, number of patients who died while awaiting transplant, type of ECMO support, timing of ECMO bridge, outcomes, survival after lung transplant.

\section{Assessment of methodological quality}

Two authors (SC and SF) independently assessed the methodological quality of the studies. They employed critical appraisal skills program (CASP) tools using the CASP checklist for case-control studies [31].

\section{Results}

\section{Study selection and characteristics}

The initial search strategy identified 82 potentially eligible studies (Figure 1); 69 studies were excluded for the following reasons: 5 involved pediatric patients, 27 were deemed not relevant and 37 were case series, reviews, letters or congress proceedings. After a hand search of the bibliographies, 14 articles met the inclusion criteria and were considered for this systematic review. All were retrospective studies.

The main characteristics of patients enrolled are summarized in Table 1 . The studies were published in the three years from 2010 to 2013, with 441 patients enrolled from 1987 to 2012. Eight studies were done in the United States [10,11,20,26,32-34], three in Italy [35-37] and one each in Sweden, Germany and France [38-40]. 
Search Strategy

Electronic literature search in Medline/PubMed and Embase from 2000 to 2014: 82

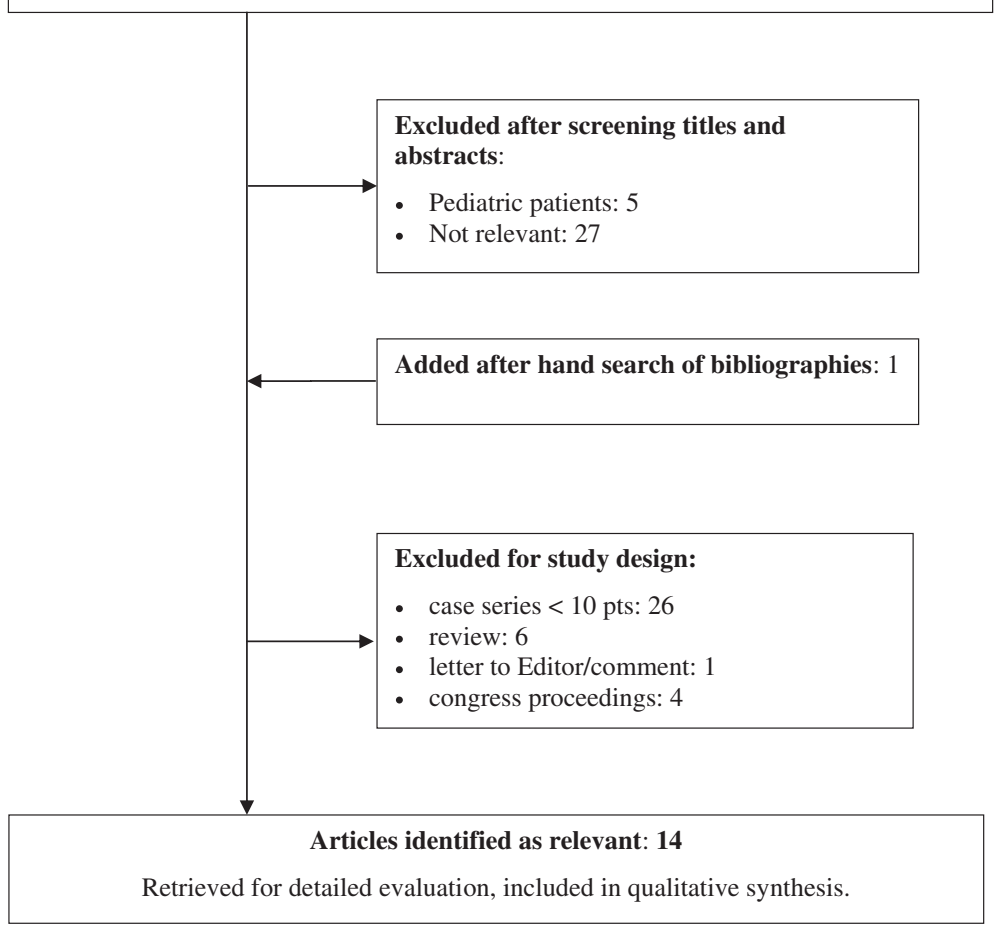

Figure 1 Flow chart of the study selection process. Pts, patients.

Ten studies reported a severity score before ECMO bridge: six reported the LAS [10,11,20,32,33,41] and four the SOFA score $[26,35,37,39]$.

In all the studies, depending on the clinical conditions, either a veno-venous or veno-arterial ECMO was used [10,11,20,26,32-41]. The strategy during ECMO bridging was invasive mechanical ventilation in four studies [33,34,40,41], and spontaneous breathing or invasive ventilation according to clinical needs in six studies [20,26,32,35-37]. Unfortunately, four studies provided no information about the ventilation strategy during ECMO bridging [10,11,38,39].

The time on ECMO bridging before lung transplantation ranged from a median of 3.2 days [34] to 16 days [39] (Table 1). Crotti et al., dividing patients according to whether the waiting time on ECMO was up to 14 days or longer, observed an ECMO bridging duration of $29.8 \pm$ 11.5 days in patients who received a transplant after waiting more than 14 days on ECMO [35].

\section{Quality of studies}

All 14 studies included were retrospective analyses. The sample size ranged from 11 [37] to 122 [10]. Eight studies were single-center trials. Seven had no control group [20,35-40]. Only six studies used the LAS system to describe the severity of their pre-bridge population
$[10,11,20,32,33,41]$. Across all 14 studies there were substantial differences in the inclusion criteria for patients, ECMO program times, and ECMO support technologies including VV and VA. Because of this, we cannot exclude a possible confounding role of some important factors such as diagnosis and comorbidity at the beginning of the bridge. Four studies [10,11,32,37] only examined patients who were successfully bridged to transplantation without mentioning patients who had died while on the waiting list.

Post-LTx complications differed among studies and were therefore not comparable. For example, six studies did not report the incidence of primary graft dysfunction. Over half presented no data on the need for postLTx mechanical ventilation (Table 2).

In addition, a learning-curve bias effect cannot be formally excluded in studies enrolling patients over a long period. Regional differences among studies in organ allocation policy, institutional differences in the logistic design and deployment criteria of extracorporeal circuits and surgeon-specific preferences about organ selection and operative technique also pose limitations for a reliable comparison. Given the substantial heterogeneity across studies we did not attempt a meta-analysis because it would not have yielded clinically meaningful results; data were descriptively summarized. 
Table 1 Characteristics of patients who underwent ECMO bridge to lung transplant and were enrolled in the selected studies

\begin{tabular}{|c|c|c|c|c|c|c|c|}
\hline Author, year & $\begin{array}{l}\text { Patients, } \\
\text { number }\end{array}$ & Age, years & $\begin{array}{l}\text { Sex male, } \\
\text { n (\%) }\end{array}$ & Diagnosis & $\begin{array}{l}\text { Ventilation } \\
\text { strategy }\end{array}$ & Bridge time, days & $\begin{array}{l}\text { Severity score } \\
\text { pre-bridge }\end{array}$ \\
\hline Mason, 2010 [11] & 51 & $39 \pm 22$ & $25(49 \%)$ & $\begin{array}{l}\text { PF 27\%; COPD 19\%; CF 12\%; PH 9.8\%; } \\
\text { sarcoidosis 2\%; other 20\% }\end{array}$ & na & na & LAS $54 \pm 21$ \\
\hline Bermudez, 2011 [34] & 17 & $40 \pm 14$ & $7(41 \%)$ & PF 35\%; Re-LTx 35\%; CF 23\%; COPD 6\% & MV & $3.2(0$ to 49$)$ & na \\
\hline Hammainen, 2011 [38] & 16 & $41 \pm 8^{\mathrm{a}}$ & $7(58 \%)^{a}$ & $\begin{array}{l}\text { PF } 37 \%^{\mathrm{a}} \text {; PH } 15 \%^{\mathrm{a}} \text {; CF } 8 \%^{\mathrm{a}} \text {; ARDS } 8 \%^{\mathrm{a}} \text {; IP } 8 \%^{\mathrm{a}} \text {; } \\
\text { PVOD } 8 \%^{\mathrm{a}} \text {; BOS } 8 \%^{\mathrm{a}} \text {; PGD } 8 \%^{\mathrm{a}}\end{array}$ & na & $12(1$ to 59$)$ & na \\
\hline Shafii, 2012 [41] & 19 & 44 (23 to 60$)$ & $10(53 \%)$ & IP 68\%; CF 16\%; PH 16\% & MV 13 & $6 \pm 5$ & LAS 87 (64 to 95) \\
\hline Nosotti, 2012 & 11 & $34 \pm 13$ & $5(45 \%)$ & na & Awake 7 MV 4 & $12.1 \pm 14.7$ & SOFA $4.9 \pm 1.4$ \\
\hline Javidfar, 2012 [20] & 18 & 34 (22 to 50$)$ & $8(45 \%)$ & CF 44\%; PF 33\%; PH 11\%; Other 11\% & Awake 6 & 11.5 (6 to 18$)$ & LAS 93 (90 to 94) \\
\hline George, 2012 [10] & 122 & $48 \pm 16$ & $74(60 \%)$ & $\begin{array}{l}\text { PF 29.5\%; CF 11.5\%; COPD 10.7\%; PH 2.5\%; } \\
\text { other 45,8\% }\end{array}$ & na & na & LAS $73.9 \pm 21.4$ \\
\hline Fuehner, 2012 [26] & 26 & 44 (23 to 62$)$ & $21(81 \%)$ & PF 35\%; PH 27\%; CF 19\%; BOS 12\%; sarcoidosis 4\% & Awake 19 MV 7 & $9(1$ to 45$)$ & SOFA 7 (6 to 12) \\
\hline Hoopes, 2013 [32] & 31 & $45 \pm 15$ & $21(67 \%)$ & $\begin{array}{l}\text { PF 29\%; CF 23\%; ILD 13\%; ARDS 10\%; PVOD 10\%; } \\
\text { PH 6\%; BOS 3\%; IP 3\%; CWP 3\% }\end{array}$ & $\begin{array}{l}\text { Ambulatory } 18 \\
13 \text { VM }\end{array}$ & 11 (2 to 53$)$ & LAS $>50$ \\
\hline Anile, 2013 [36] & 12 & na & na & CF 92\%; histiocytosis 8\% & Awake 2 MV 10 & $6 \pm 2.1$ & na \\
\hline Toyoda, 2013 [33] & 31 & $46 \pm 15^{a}$ & $10(42 \%)^{a}$ & $\begin{array}{l}\text { PF } 33 \%^{\mathrm{a}} \text {; CF } 21 \%^{\mathrm{a}} \text {; Re-LTx 13\% } \%^{\mathrm{a}} \text {; scleroderma } 13 \%^{\mathrm{a}} \text {; } \\
\text { bronchiectasis } 8 \%^{\mathrm{a}} \text {; COPD 4\% ; sarcoidosis } 4 \%^{\mathrm{a}} \text {; PH } 4 \%^{\mathrm{a}}\end{array}$ & $\mathrm{MV}^{\mathrm{a}}$ & $7.1 \pm 10$ & LAS $87 \pm 9^{a}$ \\
\hline Weig, 2013 [39] & 26 & $36(30 \text { to } 51)^{a}$ & $14(54 \%)$ & $\begin{array}{l}\text { PF 62\%; CF 23\%; COPD 4\%; Re-LTx 4\%; Lung cancer } \\
\text { 4\%; sarcoidosis 4\% }\end{array}$ & na & $16(8.8 \text { to } 25)^{a}$ & SOFA $9(8.5 \text { to } 10.5)^{a}$ \\
\hline Crotti, 2013 [35] & 25 & $41 \pm 12$ & na & PF 52\%; CF 16\%; PH 16\%; Re-LTx 12\%; ARDS 4\% & Awake $10 \mathrm{MV} 15$ & $5.8 \pm 4.5$ versus $29.8 \pm 11.5^{b}$ & SOFA $5.6 \pm 1.9$ \\
\hline Lafarge, 2013 [40] & 36 & 31 (22 to 48$)$ & $19(53 \%)$ & CF 56\%; PF 30\%; other $14 \%$ & MV & 3.5 (2 to 7 ) & na \\
\hline
\end{tabular}

Data presented in this table refer to patients underwent ECMO support with the intention to bridge to lung transplantation. ${ }^{2}$ Transplanted patients (when data for all enrolled patients are not available; Hammainen et al., all data; Toyoda, all data; Weig et al., age, ECMO bridge time and SOFA; Anile, diagnosis). ECMO bridge time (days) and the pre-bridge severity score are expressed as mean \pm standard deviation or median and range. When no descriptive cumulative data for the overall population are provided, they are calculated from raw data presented in the original papers. ${ }^{b}$ Data refer to patients divided according to waiting time on ECMO: up to 14 days or longer. Pts, patients; ECMO, extracorporeal membrane oxygenation; PF, pulmonary fibrosis; COPD, chronic obstructive pulmonary disease; CF, cystic fibrosis; PH, Pulmonary hypertension; Re-LTx, Re-lung transplantation; ARDS, acute respiratory distress syndrome; IP, interstitial pneumonia; PVOD, pulmonary veno-occlusive disease; BOS, bronchiolitis obliterans syndrome; PGD, primary graft dysfunction; ILD, interstitial lung disease; CWP, coal workers pneumoconiosis; MV, mechanical ventilation; LAS, lung allocation score; SOFA, sequential organ failure assessment; na, not available. 


\section{Survival}

The mortality rate of patients on ECMO before lung transplant was reported in ten studies and ranged between $17 \%$ and $50 \%$ with multiple organ failure, septic shock, cardiac failure and bleeding described as the most frequent causes (Table 2). Interestingly, in the study by Weig et al. liver failure developed in up to half the patients who died while awaiting lung transplant [39].

All 14 studies reported the post-transplant one-year survival rates. In five studies it ranged from $50 \%$ to $70 \%$ $[10,11,20,39,40]$, in four $70 \%$ to $90 \%[33,34,36,41]$ and in two up to $90 \%[32,38]$ (Table 2). When patients were stratified according to the ventilation strategy during ECMO bridge [37] or according to the ECMO bridge duration [35] one-year survival was significantly better in spontaneously breathing patients than mechanically ventilated ones $(85 \%$ versus $50 \%$ ) or when the ECMO bridge duration was shorter than 14 days (82\% versus 29\%). Fuehner et al. reported only a six-month survival rate of $80 \%$, for 19 patients on spontaneous breathing and 7 patients on mechanical ventilation [26]. Similarly, Hoopes et al. found high one-year survival in $26 \mathrm{ECMO}$ bridge transplanted patients, 18 of whom were ambulatory at transplantation [32].

Bermudez et al. found the survival rate in patients who received ECMO support was similar to a control group that was mechanically ventilated before transplant (74\% versus 78\%) [34]. However, they did not report the LAS score comparing the clinical status of the two groups. Nonetheless, in patients with similar LAS scores $(54 \pm 22$ and $54 \pm 21)$ Mason et al. also reported similar survival rates for those bridged with ECMO and those with mechanical ventilation (50\% and 62\%). However, this was significantly lower than for unsupported patients $(79 \%)$ although this group also had lower LAS scores $(40 \pm 11)[11]$.

Despite significantly higher LAS scores $(87 \pm 9$ versus $44 \pm 15)$ Toyoda et al. found comparable survival rates (74\% and 83\%) in the ECMO group and in patients who received the transplant without bridge support [33]. Hoopes et al. reported a post-transplant survival rate of ECMO patients comparable to or slightly higher than that of patients with a LAS score higher than 50 transplanted without bridge support, from the UNOS database [32]. In contrast, George et al. noted significantly lower survival in ECMO patients and in mechanically ventilated patients than in unsupported patients with the highest LAS quartile (58\%, 68\% and 81\%) [10]. However, survival of ECMO patients rose significantly, from $30 \%$ in 2005 to $75 \%$, in 2010 [10].

Fuehner et al., applying an awake-ECMO strategy avoiding intubation and general anesthesia, found significantly better survival than with mechanical ventilation (80\% versus 50\%) [26]. Similarly, Crotti et al. reported a survival rate of $75 \%$ in unsupported ECMO patients [35]. Although these two studies suggest that ECMO support as an alternative to invasive mechanical ventilation seems to achieve better outcomes than when combined with invasive respiratory assistance, these data come from very experienced centers and may not be generalizable. Whether ECMO alone is a better bridging strategy to lung transplant than invasive mechanical ventilation has yet to be investigated more systematically.

George et al., stratifying the data by age and by diagnosis, found that ECMO-bridged patients younger than 62 years had better one-year survival than older patients (65\% versus $38 \%)$ as did patients with chronic obstructive pulmonary disease, while patients bridged to re-lung transplant had the worst outcomes (84\% vs $40 \%)$ [10].

\section{Length of stay and ECMO-related complications}

The ICU and hospital lengths of stay were reported in six $[20,26,34,37,38,41]$ and nine studies $[10,11,20,26,32,33$, $36,37,41]$ respectively and the medians ranged from 15 to 47 days [20,34] and 22 to 47 days [20] (Table 2). With regard to the ventilation strategy Crotti et al. found that noninvasive ventilation during ECMO bridge was associated with significantly shorter ICU and hospital stays than invasive mechanical ventilation ( $31 \pm 19$ versus $84 \pm 44$ days and $52 \pm 28$ versus $119 \pm 55$ days respectively [35]. Similarly, Nosotti et al. found a shorter mean ICU stay after lung transplantation in the awake-ECMO group than the mechanically ventilated ECMO group, but the difference was not statistically significant [37].

Postoperative complications in transplanted patients before discharge from hospital are described in Table 3 . The most frequent were the need for tracheostomy (up to 77\%) [38], pulmonary graft dysfunction requiring postlung transplant ECMO (54\%) [33], pneumonia (52\%) [34], kidney failure treated with renal replacement therapy and critical illness polyneuropathy/myopathy (up to 70\%) [35]. The most frequent causes of death after lung transplantation in ECMO-bridged patients before discharge were sepsis, multiple organ failure, bleeding and primary graft dysfunction.

\section{Discussion}

This systematic review suggests that the use of ECMO support as a bridge strategy for patients awaiting lung transplant is associated with high perioperative morbidity and mortality but achieves acceptable one-year survival, very similar to that of mechanically ventilated patients. The initial goal of this systematic review was to verify the feasibility of meta-analysis of the retrieved data. However, in view of the wide heterogeneity of the selected studies we decided to make only a qualitative summary of the selected literature. The 14 studies included are not randomized trials, but retrospective analyses of case series in which the selection of patients and 


\section{Table 2 Outcomes}

\begin{tabular}{|c|c|c|c|c|c|c|}
\hline Author, year & $\begin{array}{l}\text { Ltx/total } \\
\text { patients, } n\end{array}$ & Died before Ltx, n (\%) & $\begin{array}{l}\text { Type of } \\
\text { bypass }\end{array}$ & $\begin{array}{l}\text { Survival at } \\
1 \text { yr post- } \\
\text { LTx, \% }\end{array}$ & $\begin{array}{l}\text { Length of stay } \\
\text { post-LTx, days }\end{array}$ & $\begin{array}{l}\text { MV, days } \\
\text { post-LTx }\end{array}$ \\
\hline Mason, $2010[11]$ & $51 / 51$ & na & na & $50 \%$ & $24(9$ to 55$) \mathrm{H}$ & na \\
\hline Bermudez, 2011 [34] & $14 / 17$ & 3 (17\%): neurologic dysfunction, thrombosis & W, VA & $74 \%$ & 16 (3 to 40$)$ ICU & 12 (2 to 20$)$ \\
\hline Hammainen, 2011 [38] & $13 / 16$ & 3 (19\%): septic MOF & W, VA & $92 \%$ & 22 (3 to 63 ) ICU & na \\
\hline \multirow[t]{2}{*}{ Shafii, 2012 [41] } & $14 / 19$ & 5 (26\%): septic MOF 2, DIC 2, anoxic brain injury 1 & W, VA & $75 \%$ & $42(19$ to 175$) \mathrm{H}$ & $22(5$ to 125$)$ \\
\hline & & & & & 15 (8 to 42 ) ICU & \\
\hline \multirow[t]{2}{*}{ Nosotti, 2012} & $11 / 11$ & na & W & $87 \%$ and $50 \%^{b}$ & $47.6 \pm 21.9 \mathrm{H}$ & $27.1 \pm 20.7$ \\
\hline & & & & & $30 \pm 20.4 \mathrm{ICU}$ & \\
\hline \multirow[t]{2}{*}{ Javidfar, 2012 [20] } & $10 / 18^{\mathrm{a}}$ & 8 (44\%): pneumonia 1, MOF 6, CA 1 & W,VA & $60 \%$ & $22(18$ to 33$) \mathrm{H}$ & na \\
\hline & & & & & 47 (41 to 52 ) ICU & \\
\hline George, 2012 [10] & $122 / 122$ & na & na & $57.6 \%$ & $32(16.5-60) \mathrm{H}$ & na \\
\hline \multirow[t]{2}{*}{ Fuehner, 2012 [26] } & $20 / 26$ & 6 (23\%): CA 2, septic MOF 4 & W,VA & 6-month $80 \%$ & 38 (20 to 87$) \mathrm{H}$ & 14 (0 to 64$)$ \\
\hline & & & & & 18 (1 to 69$)$ ICU & \\
\hline Hoopes, 2013 [32] & $31 / 31$ & na & $V A, W$ & $93 \%$ & $31(12 \text { to } 86)^{\mathrm{e}} \mathrm{H}$ & na \\
\hline Anile, 2013 [36] & $7 / 12$ & $5(41 \%)$ & W, VA & $85.7 \%$ & $29(15$ to 59$) \mathrm{H}$ & $<5$ \\
\hline Toyoda, 2013 [33] & $24 / 31$ & $7(22 \%)$ & W,VA & $74 \%$ & 46 median $\mathrm{H}$ & na \\
\hline Weig, 2013 [39] & $13 / 26$ & 13 (50\%): acute liver failure 7, thoracic bleeding 3, cerebral hemorrhage 1,PE 2 & W,VA & $54 \%$ & na & na \\
\hline \multirow[t]{2}{*}{ Crotti, 2013 [35] } & $17 / 25$ & 8 (32\%): MOF 3, septic shock 2, cardiogenic shock 2, intestinal ischemia 1 & W,VA & $82 \%$ and $29 \%^{c}$ & na & $12.2 \pm 11.9^{d}$ \\
\hline & & & & & & $45.3 \pm 33.5$ \\
\hline Lafarge, 2013 [40] & $30 / 36$ & 6 (17\%): Gl bleeding 1, DIC 1, cerebral hemorrhage 1, CA 1, septic shock 1, therapeutic limitation 1 & W,VA,CPB & $66.5 \%$ & na & na \\
\hline
\end{tabular}




\section{Table 3 Complications in patients discharged alive from hospital and causes of death in hospital after lung transplant}

\begin{tabular}{|c|c|}
\hline \multicolumn{2}{|r|}{ Complications in patients discharged alive from hospital } \\
\hline \multirow[t]{7}{*}{$\cdot$} & Respiratory complications: \\
\hline & PGD requiring Post-Ltx ECMO $47 \%{ }^{[34]} ; 21 \%{ }^{[41] a} ; 20 \%{ }^{[20] a} ; 54 \%{ }^{[33] a}$ \\
\hline & PGD 72 hours $3^{\text {rd }}$ grade $36 \%{ }^{[37]} ; 15 \%{ }^{[39] a} ; 35 \%{ }^{[35] a}$ \\
\hline & Tracheostomy $41 \%{ }^{[34]} ; 77 \%{ }^{[38] a} ; 64 \%{ }^{[41] a} ; 27 \%{ }^{[26]}$ \\
\hline & Bronchopleura fistula $8 \%{ }^{[38] a} ; 14 \%{ }^{[36] a}$ \\
\hline & Open chest management $50 \%{ }^{[41] a} ; 8 \%{ }^{[39] a}$ \\
\hline & Acute rejection $15 \%{ }^{[38] a} ; 28 \%{ }^{[36] a}$ \\
\hline & Acute kidney injury $35 \%{ }^{[34]} ; 12 \%{ }^{[35] a}$ \\
\hline & $\begin{array}{l}\text { Renal replacement therapy } 23 \% \%^{[34]} ; 38 \% \%^{[38] a} ; 43 \%{ }^{[41] a} ; 4 \%^{[26]} ; 14 \%{ }^{[36] a} \\
54 \% \%^{[37]} ; 12 \%{ }^{[35]}\end{array}$ \\
\hline \multicolumn{2}{|c|}{ - Infective complications: } \\
\hline & Pneumonia $52 \%{ }^{[34]}$ \\
\hline & Sepsis $23 \%{ }^{[34]} ; 19 \%^{[26]} ; 14 \%^{[36] a}$ \\
\hline \multicolumn{2}{|r|}{ - Hemorrhagic complications: } \\
\hline \multicolumn{2}{|r|}{ Gl bleeding $5 \%{ }^{[34]}$} \\
\hline \multicolumn{2}{|r|}{ Bleeding from femoral artery $5 \%{ }^{[34]}$} \\
\hline \multicolumn{2}{|r|}{ Re-op. for bleeding $15 \%{ }^{[38] a} ; 29 \%{ }^{[41] a} ; 36 \%{ }^{[37]} ; 28 \%{ }^{[36] a} ; 15 \%{ }^{[39] a}$} \\
\hline \multicolumn{2}{|r|}{ Hemorrhage $31 \%^{[26]} ; 35 \%{ }^{[35] a}$} \\
\hline \multicolumn{2}{|r|}{ Massive hemoptysis $15 \%^{[26]}$} \\
\hline \multicolumn{2}{|r|}{ - Neurological complications: } \\
\hline \multicolumn{2}{|r|}{ Cerebral hemorrhage $5 \%^{[34]}$} \\
\hline \multicolumn{2}{|r|}{ Stroke $8 \%{ }^{[38] a}$} \\
\hline \multicolumn{2}{|r|}{ Ischemia thoracic spinal cord $3 \%{ }^{[32]}$} \\
\hline \multicolumn{2}{|r|}{ CIP/CIM 31\% ${ }^{[38] a} ; 64 \%{ }^{[37]} ; 70 \%{ }^{[35] a}$} \\
\hline$\cdot$ & Digital ischemia $17 \% \%^{[34]} ; 14 \%{ }^{[36] a}$ \\
\hline
\end{tabular}

Causes of death in hospital after LTX

- MOF 6\% ${ }^{[34]} ; 15 \%{ }^{[26] ;} 7 \%^{[40] a}$

- Sepsis $18 \%^{[34]} ; 14 \%^{[41] a} ; 10 \%{ }^{[40] a}$

- Acute colonic rupture 8\% ${ }^{[38] a}$

- Cardiogenic shock 6\% ${ }^{[34]}$

- Cardiac arrest 10\% ${ }^{[40] a}$

- Bleeding 9\% ${ }^{[37]} ; 31 \%^{[39] a} ; 3 \%{ }^{[40] a}$

- Neurological event 3\% ${ }^{[32]}$

- Lung cancer 5\% ${ }^{[26]}$

- Bronchopleural fistula $3 \%{ }^{[40] a}$

- PGD 31\% [39]a

- Open chest treatment 23\% ${ }^{[39] a}$

- Other 18\% ${ }^{[35] a}$

a percentages of transplanted patients: Shafii et al., Hammainen et al., Javidfar et al., Toyoda et al., Crotti et al., Anile et al., Lafarge et al., Weig et al.. When the percentages of complications were not available, complications referring to the overall enrolled population are reported.

ECMO, Extracorporeal membrane oxygenation; Post-LTx, Post-lung transplantation; PGD, Primary graft dysfunction; Gl, Gastrointestinal; MOF, Multi-organ failure; Re-op., Re-operation; CIP/CIM, Critical illness polyneuropathy/critical illness myopathy.
ECMO treatment were discretional to the center and not homogeneous, thus possibly affecting the efficacy of the treatment and certainly preventing the results being evaluated in a meta-analysis.

Lung transplantation is the only option for patients with end-stage lung failure. However, organ supply is grossly inadequate compared to the large numbers of patients awaiting transplant, so mortality in the waiting list is still very high [11]. In this setting, mechanical ventilation and ECMO are the only supportive strategies available to prolong these patients' lives, increasing their chances of receiving suitable organs.

Although the main benefit of mechanical ventilation is to improve gas exchange [12], it can in fact open the way to pulmonary infection, sepsis and muscle atrophy, prolonging weaning after lung transplant and making it difficult $[11,42,43]$. ECMO, on the other hand, could potentially provide adequate respiratory and hemodynamic support, with fewer of the side effects of mechanical ventilation in patients awaiting lung transplant, offering an alternative bridging strategy $[7,13,19,20,22,44]$. However, many transplant centers still consider ECMO a contraindication to lung transplant given the mixed outcomes in patients transplanted from ECMO [6]. This systematic review found that ECMO-bridged patients had satisfactory post-transplant survival, similar to patients bridged with mechanical ventilation. ECMO has helped to save numerous high-risk transplant candidates with otherwise acutely lethal conditions.

Proper patient selection for ECMO is clearly essential for a good long-term outcome. In the studies reviewed here, ECMO was not considered suitable for patients with sepsis, neurologic impairment, profound malnutrition [41] or severe graft dysfunction after lung transplantation [33], whereas advanced age ( $>50$ years) was not a contraindication [41]. The clinical conditions of patients supported with pre-transplant ECMO are usually more critical than those of the population awaiting lung transplant and this may have a negative influence on their overall outcome [16]. However, this systematic review found that at least in selected reports the post-transplant outcome of ECMObridged patients was comparable to recipients who did not receive pre-transplant support. Any excessive reduction of the post-transplant survival rate of ECMO-bridged recipients would obviously defeat the principle of allocating transplantable lungs on the basis not only of the severity of their clinical condition, but also the potential long-term benefit. The definition of clinical parameters predicting survival for ECMO-bridged patients would certainly help clarify this problematic question $[22,45]$.

In most of the studies reviewed patients bridged with ECMO were also supported with mechanical ventilation, thus combining two invasive means of respiratory support, each with potentially harmful side effects. Recent reports do suggest that invasive mechanical ventilation 
may still be considered an effective bridge. Mason et al. showed that the unadjusted post-transplant survival at one year was $62 \%$ for recipients bridged with mechanical ventilation, 50\% for those bridged with ECMO, and 79\% for unsupported patients [11]. Vermeijden et al. compared the outcomes of 13 lung transplant recipients bridged with invasive mechanical ventilation with 70 controls who received no pre-transplant support [46]. Interestingly, the two groups had similar post-transplant survival and incidence of primary graft dysfunction.

To further improve the outcome for ECMO-bridged patients, therefore, it has been proposed that non-invasive ventilation should be used rather than invasive mechanical ventilation. This could minimize the muscular deconditioning and ventilator-associated morbidity [42,47-49]. Furthermore, the possibility of keeping patients awake could avoid the hemodynamic consequences of general anesthesia and positive-pressure ventilation, especially in those with pulmonary hypertension. The study that enrolled patients bridged to transplant with ECMO as an alternative to invasive mechanical ventilation did in fact find significantly better six-month survival with ECMO than with mechanical ventilation (62\% versus $35 \%$ ) [26]; this suggests that preserving spontaneous breathing may keep patients in a better condition, with fewer of the drawbacks of mechanical ventilation.

Among the factors that can affect post-transplant outcome in patients bridged with ECMO, the most frequent are the duration of the bridge and the timing of the lung transplant [6]. Although patients can tolerate ECMO for long periods $[34,50,51]$, any extra waiting time may significantly increase mortality [35]. Crotti et al. showed that patients who received a lung transplant after waiting more than 14 days had significantly higher rates of mortality and morbidity. ECMO-bridged patients should therefore be routinely re-assessed to make sure there are no exclusion criteria for lung transplantation, in order to optimize outcomes and avoid futile transplants [16].

The incidence of complications in ECMO patients awaiting lung transplant was similar to those previously reported in patients receiving ECMO for acute respiratory or cardiogenic shock [52]. It was not possible to compare the ICU and hospital lengths of stay for ECMO and non-ECMO patients because most of the studies gave no figures for the control group. Only two studies reported a shorter hospital stay for patients receiving awake-ECMO than for those given mechanical ventilation $[26,35]$.

These observations suggest that ECMO might make it easier to optimize the clinical conditions of transplant candidates, mainly for more active participation in the activities of daily living, including ambulation, despite their critical respiratory illness. However, the length of stay depends on many factors, such as hospital mortality, which are not necessarily directly linked to support with ECMO or mechanical ventilation.

\section{Limitations}

The present systematic review has several limitations. First, the studies included are not controlled or randomized trials but retrospective analyses of case series, with broad heterogeneity. Clearly, observational studies rarely provide sufficiently robust evidence to recommend changes to clinical practice or health policy decisionmaking. However, they are the only ones that provide any useful evidence for certain topics [31].

Second, the ventilatory strategy of the patients on ECMO bridging is not described (in terms of endexpiratory positive pressure, tidal volume, inspiratory pressure). Third, indications, type and duration of ECMO bridging differed among studies and some patients may have been described twice because they were reported in different studies $[10,11,33,34,41]$. Fourth, although we confined our literature search to the year 2000 onward because subsequent important advances were made in the technology for ECMO devices and mechanical ventilation recommendations that could have mixed up the results, three studies $[11,34,36]$ enrolled patients before this period. Fifth, other extracorporeal life support strategies, potentially more easily manageable than ECMO, such as the artero-venous low flow extracorporeal carbon dioxide removal [53], the pulmonary artery-left atrium para-corporeal circuit configuration [54], and the minimally invasive low blood flow carbon dioxide removal systems [55], have been used as bridge to lung transplantation, but were excluded from this systematic review. The continuous technological advancement in the field of extracorporeal life support provides progressively more innovative devices, with the purpose to better suit specific patient populations. However, the notable difference of these newer strategies from ECMO in terms of management, complexity, and contribution to gas exchange, suggest they should be considered as a separate issue.

\section{Conclusions}

Since its first application as a bridge to lung transplantation in patients with decompensating acute respiratory failure, ECMO support has gradually been used more frequently not only as salvage therapy, but also as a very promising alternative bridging strategy to mechanical ventilation, allowing more physiological respiratory assistance. However, given the quality and the wide heterogeneity among studies in this complex field, current clinical evidence does not permit any firm conclusions on the efficacy of ECMO as a bridge to lung transplantation in addition, or as an alternative to mechanical ventilation, and further prospective, more systematic multicenter trials 
are awaited. Future studies should ideally consider ECMO as part of a global algorithm of care for patients with endstage lung disease, aiming at keeping them eligible for transplant despite refractoriness to maximal medical therapy, rather than just as an isolated means of respiratory support.

\section{Key messages}

- Patients awaiting lung transplant are at high risk of death

- Mechanical ventilation can be required in end-stage severe acute respiratory failure

- ECMO support has been proposed as an alternative bridging strategy to mechanical ventilation

- ECMO support may provide acceptable one-year survival

- ECMO support should be part of a global algorithm of care for these patients

\begin{abstract}
Abbreviations
ARDS: acute respiratory distress syndrome; BOS: bronchiolitis obliterans syndrome; CA: cardiac arrest; CF: cystic fibrosis; CIP/CIM: critical illness polyneuropathy/critical illness myopathy; COPD: chronic obstructive pulmonary disease; CPB: cardiopulmonary by-pass; CWP: coal workers pneumoconiosis; DIC: disseminated intravascular coagulation; ECMO: extracorporeal membrane oxygenation; Gl: gastrointestinal; H: hospital; ILD: interstitial lung disease; IP: interstitial pneumonia; LAS: lung allocation score; LOS: length of stay; LTX: lung transplant; MOF: multi-organ failure; MV: mechanical ventilation; PE: pulmonary embolism; PF: pulmonary fibrosis; PGD: primary graft dysfunction; PH: pulmonary hypertension; Post-LTx: post-lung transplantation; Pts: patients; PVOD: pulmonary veno-occlusive disease; Re-LTx: re-lung transplantation; Re-op: re-operation; SOFA: sequential organ failure assessment; UNOS: United Network of Organ Sharing; VA: veno-arterial; W: veno-venous; NA: not available.
\end{abstract}

\section{Competing interests}

The authors declare that they have no competing interests.

\section{Authors' contributions}

All the authors conceived and designed the systematic review. DC, SC, SF screened citation titles and abstracts to identify potentially eligible papers. SC, SF abstracted data in duplicate from the articles retrieved. AC collected the information from the articles retrieved in a datasheet. DC, SC, SF, LD wrote the paper. All authors read and approved the final manuscript.

\section{Acknowledgements}

The authors thank Dario Consonni for statistical consulting - Unità Operativa di Epidemiologia, Fondazione IRCCS Ca' Granda-Ospedale Maggiore Policlinico, Milano. The authors have no support or funding to report.

\footnotetext{
Author details

'Dipartimento di Anestesia, Rianimazione (Intensiva e Subintensiva) e Terapia del Dolore, Fondazione IRCCS Ca' Granda, Ospedale Maggiore Policlinico, Via F. Sforza 35, 20122 Milano, Italy. ${ }^{2}$ Dipartimento di Fisiopatologia Medico-Chirurgica e dei Trapianti, Università degli Studi di Milano, Milano, Italy. ${ }^{3}$ Interdepartmental Division of Critical Care Medicine, University of Toronto, Toronto, Canada. ${ }^{4}$ Dipartimento di Anestesiologia e Medicina degli Stati Critici, Università di Torino, Torino, Italy.
}

Received: 18 August 2014 Accepted: 20 November 2014

Published online: 22 January 2015

\section{References}

1. Myles PS, Snell GI, Westall GP: Lung transplantation. Curr Opin Anaesthesiol 2007, 20:21-26.

2. Cooper JD, Pearson FG, Patterson GA, Todd TR, Ginsberg RJ, Goldberg M, DeMajo WA: Technique of successful lung transplantation in humans. J Thorac Cardiovasc Surg 1987, 93:173-181.

3. Christie JD, Edwards LB, Kucheryavaya AY, Benden C, Dobbels F, Kirk R, Rahmel AO, Stehlik J, Hertz MI: The Registry of the International Society for Heart and Lung Transplantation: Twenty-eighth Adult Lung and Heart-Lung Transplant Report-2011. J Heart Lung Transplant 2011, 30:1104-1122.

4. Diaz-Guzman E, Hoopes CW, Zwischenberger JB: The evolution of extracorporeal life support as a bridge to lung transplantation. ASAIO J 2013, 59:3-10.

5. Kreider M, Hadjiliadis D, Kotloff RM: Candidate selection, timing of listing, and choice of procedure for lung transplantation. Clin Chest Med 2011, 32:199-211.

6. Orens JB, Estenne M, Arcasoy S, Conte JV, Corris P, Egan JJ, Egan T, Keshavjee S, Knoop C, Kotloff R, Martinez FJ, Nathan S, Palmer S, Patterson A, Singer L, Snell G, Studer S, Vachiery JL, Glanville AR, Pulmonary Scientific Council of the International Society for Heart and Lung Transplantation: International guidelines for the selection of lung transplant candidates: 2006 update-a consensus report from the Pulmonary Scientific Council of the International Society for Heart and Lung Transplantation. $J$ Heart Lung Transplant 2006, 25:745-755.

7. Hoeper MM, Granton J: Intensive care unit management of patients with severe pulmonary hypertension and right heart failure. Am J Respir Crit Care Med 2011, 184:1114-1124.

8. Cortes I, Penuelas O, Esteban A: Acute respiratory distress syndrome: evaluation and management. Minerva Anestesiol 2012, 78:343-357.

9. De Prost N, Dreyfuss D: How to prevent ventilator-induced lung injury? Minerva Anestesiol 2012, 78:1054-1066.

10. George TJ, Beaty CA, Kilic A, Shah PD, Merlo CA, Shah AS: Outcomes and temporal trends among high-risk patients after lung transplantation in the United States. J Heart Lung Transplant 2012, 31:1182-1191.

11. Mason DP, Thuita L, Nowicki ER, Murthy SC, Pettersson GB, Blackstone EH: Should lung transplantation be performed for patients on mechanical respiratory support? The US experience. J Thorac Cardiovasc Surg 2010, 139:765-773.

12. Singer JP, Blanc PD, Hoopes C, Golden JA, Koff JL, Leard LE, Cheng S, Chen $\mathrm{H}$ : The impact of pretransplant mechanical ventilation on short- and long-term survival after lung transplantation. Am J Transplant 2011, 11:2197-2204.

13. Strueber M: Bridges to lung transplantation. Curr Opin Organ Transplant 2011, 16:458-461.

14. Veith FJ: Lung transplantation. Transplant Proc 1977, 9:203-208.

15. Zapol WM, Snider MT, Hill JD, Fallat RJ, Bartlett RH, Edmunds LH, Morris AH, Peirce EC 2nd, Thomas AN, Proctor HJ, Drinker PA, Pratt PC, Bagniewski A, Miller RG Jr: Extracorporeal membrane oxygenation in severe acute respiratory failure. A randomized prospective study. JAMA 1979, 242:2193-2196.

16. Javidfar J, Bacchetta M: Bridge to lung transplantation with extracorporeal membrane oxygenation support. Curr Opin Organ Transplant 2012, 17:496-502.

17. Riley JB, Scott PD, Schears GJ: Update on safety equipment for extracorporeal life support (ECLS) circuits. Semin Cardiothorac Vasc Anesth 2009, 13:138-145.

18. Braune SA, Kluge S: Extracorporeal lung support in patients with chronic obstructive pulmonary disease. Minerva Anestesiol 2013, 79:934-943.

19. Del Sorbo L, Ranieri VM, Keshavjee S: Extracorporeal membrane oxygenation as "bridge" to lung transplantation: what remains in order to make it standard of care? Am J Respir Crit Care Med 2012, 185:699-701

20. Javidfar J, Brodie D, Iribarne A, Jurado J, Lavelle M, Brenner K, Arcasoy S, Sonett J, Bacchetta M: Extracorporeal membrane oxygenation as a bridge to lung transplantation and recovery. J Thorac Cardiovasc Surg 2012, 144:716-721.

21. MacLaren G, Brain MJ, Butt WW: ECMO in acute and chronic adult respiratory failure: recent trends and future directions. Minerva Anestesiol 2013, 79:1059-1065.

22. Strueber M: Extracorporeal support as a bridge to lung transplantation. Curr Opin Crit Care 2010, 16:69-73. 
23. Kreider M, Kotloff RM: Selection of candidates for lung transplantation. Proc Am Thorac Soc 2009, 6:20-27.

24. Egan TM, Murray S, Bustami RT, Shearon TH, McCullough KP, Edwards LB, Coke MA, Garrity ER, Sweet SC, Heiney DA, Grover FL: Development of the new lung allocation system in the United States. Am J Transplant 2006, 6:1212-1227.

25. Ambrosino N, Makhabah DN: Comprehensive physiotherapy management in ARDS. Minerva Anestesiol 2013, 79:554-563.

26. Fuehner T, Kuehn C, Hadem J, Wiesner O, Gottlieb J, Tudorache I, Olsson KM, Greer M, Sommer W, Welte T, Haverich A, Hoeper MM, Warnecke G: Extracorporeal membrane oxygenation in awake patients as bridge to lung transplantation. Am J Respir Crit Care Med 2012, 185:763-768.

27. Garcia JP, Kon ZN, Evans C, Wu Z, lacono AT, McCormick B, Griffith BP: Ambulatory veno-venous extracorporeal membrane oxygenation: innovation and pitfalls. J Thorac Cardiovasc Surg 2011, 142:755-761.

28. McGrane S, Pandharipande PP: Sedation in the intensive care unit. Minerva Anestesiol 2012, 78:369-380.

29. Olsson KM, Simon A, Strueber M, Hadem J, Wiesner O, Gottlieb J, Fuehner T, Fischer S, Warnecke G, Kuhn C, Haverich A, Welte T, Hoeper MM: Extracorporeal membrane oxygenation in nonintubated patients as bridge to lung transplantation. Am J Transplant 2010, 10:2173-2178.

30. PRISMA transparent reporting of systematic reviews and meta-analysis. [http://www.prisma-statement.org]

31. Check-list for case control-studies. [http://www.casp-uk.net]

32. Hoopes CW, Kukreja J, Golden J, Davenport DL, Diaz-Guzman E, Zwischenberger JB: Extracorporeal membrane oxygenation as a bridge to pulmonary transplantation. J Thorac Cardiovasc Surg 2013, 145:862-867.

33. Toyoda Y, Bhama JK, Shigemura N, Zaldonis D, Pilewski J, Crespo M, Bermudez C: Efficacy of extracorporeal membrane oxygenation as a bridge to lung transplantation. J Thorac Cardiovasc Surg 2013, 145:1065-1070.

34. Bermudez CA, Rocha RV, Zaldonis D, Bhama JK, Crespo MM, Shigemura N, Pilewski JM, Sappington PL, Boujoukos AJ, Toyoda Y: Extracorporeal membrane oxygenation as a bridge to lung transplant: midterm outcomes. Ann Thorac Surg 2011, 92:1226-1231.

35. Crotti S, lotti GA, Lissoni A, Belliato M, Zanierato M, Chierichetti M, Di Meo G, Meloni F, Pappalettera M, Nosotti M, Santambrogio L, Viganò M, Braschi A, Gattinoni L: Organ allocation waiting time during extracorporeal bridge to lung transplant affects outcomes. Chest 2013, 144:1018-1025.

36. Anile M, Diso D, Russo E, Patella M, Carillo C, Pecoraro Y, Onorati I, Pugliese F, Ruberto F, De Giacomo T, Angioletti D, Mantovani S, Mazzesi G, Frati G, Rendina EA, Venuta F: Extracorporeal membrane oxygenation as bridge to lung transplantation. Transplant Proc 2013, 45:2621-2623.

37. Nosotti M, Rosso L, Tosi D, Palleschi A, Mendogni P, Nataloni IF, Crotti S, Tarsia P: Extracorporeal membrane oxygenation with spontaneous breathing as a bridge to lung transplantation. Interact Cardiovasc Thorac surg 2013, 16:55-59.

38. Hammainen P, Schersten H, Lemstrom K, Riise GC, Kukkonen S, Sward K, Sipponen J, Silverborn M, Dellgren G: Usefulness of extracorporeal membrane oxygenation as a bridge to lung transplantation: a descriptive study. J Heart Lung Transplant 2011, 30:103-107.

39. Weig T, Irlbeck M, Frey L, Zwissler B, Winter H, Preissler G, Schramm R, Neurohr C, Dolch ME: Parameters associated with short- and midterm survival in bridging to lung transplantation with extracorporeal membrane oxygenation. Clin Transplant 2013, 27:E563-E570.

40. Lafarge M, Mordant P, Thabut G, Brouchet L, Falcoz PE, Haloun A, Le Pimpec-Barthes F, Maury JM, Reynaud-Gaubert M, Saint-Raymond C, Sage E, Stern M, Thomas $P$, Castier $Y$, Dorent R, Mal H: Experience of extracorporeal membrane oxygenation as a bridge to lung transplantation in France. J Heart Lung Transplant 2013, 32:905-913.

41. Shafii AE, Mason DP, Brown CR, Vakil N, Johnston DR, McCurry KR, Pettersson GB, Murthy SC: Growing experience with extracorporeal membrane oxygenation as a bridge to lung transplantation. ASAIO J 2012, 58:526-529.

42. Chastre J, Fagon JY: Ventilator-associated pneumonia. Am J Respir Crit Care Med 2002, 165:867-903.

43. Del Sorbo L, Boffini M, Rinaldi M, Ranieri VM: Bridging to lung transplantation by extracorporeal support. Minerva Anestesiol 2012 78:243-250

44. Pesenti A, Zanella A, Patroniti N: Extracorporeal gas exchange. Curr Opin Crit Care 2009, 15:52-58
45. Russo MJ, Davies RR, Hong KN, Iribarne A, Kawut S, Bacchetta M, D'Ovidio F, Arcasoy S, Sonett JR: Who is the high-risk recipient? Predicting mortality after lung transplantation using pretransplant risk factors. J Thorac Cardiovasc Surg 2009, 138:1234-1238.

46. Vermeijden JW, Zijlstra JG, Erasmus ME, van der Bij W, Verschuuren EA: Lung transplantation for ventilator-dependent respiratory failure. J Heart Lung Transplant 2009, 28:347-351.

47. Turner DA, Cheifetz IM, Rehder KJ, Williford WL, Bonadonna D, Banuelos SJ, Peterson-Carmichael S, Lin SS, Davis RD, Zaas D: Active rehabilitation and physical therapy during extracorporeal membrane oxygenation while awaiting lung transplantation: a practical approach. Crit Care Med 2011, 39:2593-2598.

48. Morris PE, Goad A, Thompson C, Taylor K, Harry B, Passmore L, Ross A, Anderson L, Baker S, Sanchez M, Penley L, Howard A, Dixon L, Leach S, Small R, Hite RD, Haponik E: Early intensive care unit mobility therapy in the treatment of acute respiratory failure. Crit Care Med 2008, 36:2238-2243.

49. Schweickert WD, Pohlman MC, Pohlman AS, Nigos C, Pawlik AJ, Esbrook CL, Spears L, Miller M, Franczyk M, Deprizio D, Schmidt GA, Bowman A, Barr R, McCallister KE, Hall JB, Kress JP: Early physical and occupational therapy in mechanically ventilated, critically ill patients: a randomised controlled trial. Lancet 2009, 373:1874-1882.

50. Aigner C, Wisser W, Taghavi S, Lang G, Jaksch P, Czyzewski D, Klepetko W: Institutional experience with extracorporeal membrane oxygenation in lung transplantation. Eur J Cardiothorac Surg 2007, 31:468-473.

51. Broome M, Palmer K, Schersten H, Frenckner B, Nilsson F: Prolonged extracorporeal membrane oxygenation and circulatory support as bridge to lung transplant. Ann Thorac Surg 2008, 86:1357-1360.

52. Zangrillo A, Landoni G, Biondi-Zoccai G, Greco M, Greco T, Frati G, Patroniti N, Antonelli M, Pesenti A, Pappalardo F: A meta-analysis of complications and mortality of extracorporeal membrane oxygenation. Crit Care Resusc 2013, 15:172-178.

53. Fischer S, Simon AR, Welte T, Hoeper MM, Meyer A, Tessmann R, Gohrbandt B, Gottlieb J, Haverich A, Strueber M: Bridge to lung transplantation with the novel pumpless interventional lung assist device NovaLung. J Thorac Cardiovasc Surg 2006, 131:719-723.

54. Strueber M, Hoeper MM, Fischer S, Cypel M, Warnecke G, Gottlieb J, Pierre A, Welte T, Haverich A, Simon AR, Keshavjee S: Bridge to thoracic organ transplantation in patients with pulmonary arterial hypertension using a pumpless lung assist device. Am J Transplant 2009, 9:853-857.

55. Ricci D, Boffini M, Del Sorbo L, El Qarra S, Comoglio C, Ribezzo M, Bonato R, Ranieri VM, Rinaldi M: The use of $\mathrm{CO} 2$ removal devices in patients awaiting lung transplantation: an initial experience. Transplant Proc 2010, 42:1255-1258.

\section{Submit your next manuscript to BioMed Central and take full advantage of:}

- Convenient online submission

- Thorough peer review

- No space constraints or color figure charges

- Immediate publication on acceptance

- Inclusion in PubMed, CAS, Scopus and Google Scholar

- Research which is freely available for redistribution

Submit your manuscript at www.biomedcentral.com/submit
C Biomed Central 